\title{
Group Cohesiveness, Social Norms, and Bystander Intervention
}

\author{
Gregory K. Rutkowski, Charles L. Gruder, and Daniel Romer \\ University of lllinois at Chicago
}

\begin{abstract}
Previous research suggests that the larger a group of bystanders is, the less likely any one bystander is to offer a victim help in an emergency. Nearly all of this research has been conducted with unacquainted bystanders, and thus, an important group characteristic, cohesiveness, may have been held at a low level. Study 1 found support for the hypothesis that group size inhibits helping in lowcohesive groups but facilitates helping in high-cohesive groups. Study 2 found support for the hypothesis that the effects of cohesiveness on bystander intervention depend on the salience of the social-responsibility norm: Cohesiveness facilitated helping more when the social-responsibility norm was salient than when it was not. Thus, group cohesiveness is a theoretically critical variable for understanding the bystander effect. The results of these experiments suggest that the effects of group and situation variables depend on the group's meaning to the individual.
\end{abstract}

Latané and Darley (1970) conducted a series of investigations to test the relation between group size and aid giving in an emergency situation. They found that the greater the number of bystanders, the lower the likelihood of anyone helping. Put another way, an individual was more likely to help when alone than when in the presence of others. This has come to be known as the bystander effect. In order to account for this effect, Latané and Darley invoked the concept of diffusion of responsibility. According to this notion, the more bystanders present, the less each one feels responsible to help. A single individual faced with an emergency bears the sole responsibility for assisting the victim. If others are present, the responsibility is not focused uniquely on any one of the group members; instead, it is shared among all of them.

In nearly all of the research conducted to study the bystander effect, the bystanders were strangers at the time of the emergency (Latané \& Nida, 1981). An important characteristic of such groups is that they are low in cohesiveness. Cohesiveness is typically de-

Study 1 constituted the research for the first author's master's thesis. The authors thank Harry Upshaw for his advice and comments.

The Office of Social Science Research at the University of Illinois at Chicago provided support for this research.

Requests for reprints should be sent to Charles $L$. Gruder, Department of Psychology, University of Illinois at Chicago, Box 4348, Chicago, Illinois 60680. fined as the degree of attraction group members have for one another (Cartwright, 1968; Lott \& Lott, 1965). Cohesiveness has been shown to increase responsiveness to social norms (Berkowitz, 1954; Dion, Miller, \& Magnan, 1971). One norm that is assumed to be prevalent in our culture is the norm of social responsibility. According to this norm, people should help others who are in need of help and who are dependent on them for it (Berkowitz, 1972; Berkowitz \& Daniels, 1963). The more salient this norm, the more help that is given to persons in need (Berkowitz, 1972; Gruder, Romer, \& Korth, 1978; Schwartz, 1975). Thus, greater cohesiveness among bystanders should make them more responsive to the social-responsibility norm and, therefore, more likely to help in an emergency.

It is the influence of group cohesiveness in combination with the social-responsibility norm that is the focus of this research. We hypothesized that cohesiveness is likely to cancel the negative effect of diffusion of responsibility in a group of bystanders by increasing the bystanders' adherence to the social-responsibility norm. ${ }^{1}$ Moreover, Jones

\footnotetext{
I The suggestion that cohesiveness may affect diffusion of responsibility is also supported by findings in riskyshift research. For example, Dion, Miller, and Magnan (1971) found that high cohesiveness inhibited the risky shift, presumably by increasing personal responsibility, whereas low cohesiveness enhanced risk taking by facilitating diffusion of responsibility.
} 
and Gerard (1967) pointed out that in cohesive groups, the importance of social norms and pressure to conform to them may increase as group size increases (especially from dyads to groups of three or four). Hence, cohesiveness can be expected to reverse the bystander effect such that the bystander is more likely to help when there are more people around than when there are fewer.

There is evidence supporting the suggestion that group cohesiveness may play an important role in facilitating altruistic behavior. Darley and Latané (1968), for example, found that groups composed of friends were more likely to intervene and help in an emergency than groups composed of strangers. Because friends are highly attracted to each other, they may be considered a cohesive group. Gottlieb and Carver (1980) found that the negative effect of group size was insignificant when group members expected future interaction with each other (including the victim). The anticipation of face-to-face interaction with other bystanders was assumed to increase the potential for being blamed for inaction, thus motivating helping. Alternatively, the expectation of future interaction may have induced a moderate degree of cohesiveness in the group members, thus enhancing their compliance with social norms.

It should be noted, however, that Darley and Latane (1968) as well as Gottlieb and Carver (1980) failed to separate the role of the victim from that of another group member. That is, in their studies the victim was always one of the other bystanders. This consideration appears particularly important in Gottlieb and Carver's study because it is not clear whether the critical factor inhibiting the diffusion of blame was the expectation of future interaction with other bystanders or with the victim. If cohesiveness increases adherence to social norms, then we would expect it to increase helping even when the victim is not a group member.

The main purpose of the first study was to assess the impact of group cohesiveness on the bystander effect. Consistent with the diffusion-of-responsibility hypothesis, group size should inhibit helping in low-cohesive groups, thus replicating the frequently found bystander effect. When cohesiveness is high, however, personal responsibility for helping should increase as group size increases. This should reverse the bystander effect so that the bystander is more likely to give help when there are more rather than fewer bystanders.

\section{Study 1}

\section{Method}

Subjects. A total of 144 male undergraduates volunteered for the experiment and received course credit in return for their participation.

Design. Two- and four-person groups were constituted and then randomly assigned to two cohesiveness conditions in a $2 \times 2$ (Cohesiveness $\times$ Group Size) factorial design, with 36 subjects in each condition.

These particular group sizes were chosen for the following reasons. Morgan (1978) showed that with groups of six or seven, the diffusion-of-responsibility effect becomes less pronounced unless individual costs of intervention are high. Because the costs of helping in this study were relatively low, the effect could be expected to be more pronounced when comparing groups of small to moderate size (i.e., from two to four). Also, as noted earlier, these sizes seem optimal for detecting the effects of group norms.

Procedure. Groups of six subjects reported to the laboratory, and cohesiveness was manipulated as follows: In the high-cohesiveness condition, subjects were given exercises designed to induce group cohesiveness (Pfeiffer \& Jones, 1980). The experimenter asked the subjects to introduce themselves and say a few words about their major field of study. He then introduced several topics to the subjects and requested that they take a few minutes to think about them. These topics included likes and dislikes about college, extracurricular activities, student housing, and social and family life. After a few moments, the experimenter encouraged the subjects to talk about these topics and share their feelings with one another. The experimenter indicated that this discussion would be tape-recorded. At the end of the 20-minute session, the experimenter asked the participants to find at least three ways in which they were similar to one another. During the entire session, the experimenter was minimally involved, thus ensuring that the subjects focused their attention only on each other.

The low-cohesiveness condition differed in that the subjects did not interact with one another. They were asked to listen to a tape recording from a high-cohesivegroup discussion, thereby yoking each low-cohesive group with a high-cohesive group.

The six subjects were then informed that several experiments were being run simultaneously, with one group of two subjects working in one part of the building and another group of four subjects working in a different location. The two- and four-person groups were then randomly determined by drawing slips of paper. ${ }^{2}$

\footnotetext{
${ }^{2}$ Because this procedure yielded more subjects in the four- than in the two-person groups, it was necessary to run additional subjects in two-person groups. This was done by conducting three additional sessions in each cohesiveness condition, with 3 two-person groups in each session.
} 
Subjects were next taken to the control room, where the emergency would later take place. Some pieces of maintenance equipment were strewn about the floor in a corner of the room. The future victim appeared to be doing maintenance work while standing on a ladder, facing the wall. Without calling attention to the victim, the experimenter passed through the control room, thus making the subjects aware of the victim's presence and location. To ensure that exposure to the victim was equivalent in both group-size conditions, only two subjects at a time were taken to the control room.

Each group of two or four subjects was told that they would remain in this laboratory while the other group participated in a different experiment on the other side of the building. Thus, all subjects in fact remained close to the control room where the emergency later occurred. They were informed that their experiment was on group decision making under conditions of limited communication and told that to create conditions of limited communication, they would be separated from one another in rooms connected by an intercom system. Actually, the reason for the separation was to eliminate the effects of social influence and modeling processes (Bryan \& Test, 1967; Latané \& Darley, 1970; Ross, 1970).

Subjects were told that they would first work individually on the dilemma-of-choice problems (Kogan \& Wallach, 1964) and that later the group would discuss. their answers over the intercom. To minimize expectations of future interaction (Gottlieb \& Carver, 1980), the experimenter indicated that after the discussion, the subjects would not see each other again. Then the experimenter pointed to the intercom control panel and explained that there were two settings under his control: one for subjects to listen to the experimenter and the other for subjects to speak to each other and the experimenter. Then, one at a time, the subjects were brought into their rooms. This prevented them from knowing where the others were located. The reason for this was to block each subject from communicating with others during the emergency, thus ensuring independence of subjects' responses and permitting individual subjects to be the unit of analysis. After each individual had been seated in his room, the experimenter returned to the laboratory and proceeded with the remaining subjects in the same fashion. In order to prevent interaction among those waiting their turn to be taken to their rooms, a questionnaire was administered and the subjects were asked to start working on them immediately and not to talk.

After all subjeets were seated in their rooms, the experimenter addressed them over the intercom. Actually, from this point on, the subjects were listening through headphones to a tape recording. The experimenter explained that he was back in the control room and suggested that subjects begin looking at their problems. He next announced that he had to leave the room to take care of the other group on the other side of the building and would be back in 15 minutes. The purpose of this was ostensibly to remove the obviously responsible experimenter from the scene of the emergency. The experimenter assured subjects that on his return, the microphones would be turned on so that they could talk to each other and to him, but in the meantime, they would not be able to communicate with each other.

Some noise was made to mark the exit of the experimenter. Because the intercom system was apparently left on, the subjects could overhear what was going on in the control room. About 120 seconds after the experimenter's apparent departure, the emergency began. The subjects heard a loud crash and a scream: "Oh, my God, my ankle. . . . I . . . I I can't move it. Oh . . . my . . . leg. . . . I . . . can't get this . . . off me." The maintenance worker moaned for about 60 seconds and gradually became quiet. After 120 seconds the emergency situation ended and the tape recorder was turned off. Those who left their rooms to see if the worker needed help were asked to return to their rooms. Nonintervening subjects were interrupted in their rooms and all subjects were individually probed for suspicion, given a postexperimental questionnaire, and informed of the true nature of the experiment.

Dependent measures. Subjects were considered to have helped if they left their rooms, presumably to aid the victim or call for help. This was recorded automatically by an electric switch mounted on the door frame, which was connected to an Esterline Angus operation recorder (Model A 620X). Both the operation recorder and the recording of the emergency were turned on at the same time. The subject's opening of the door was recorded on the record chart.

The two dependent measures of helping were the number of subjects who attempted to intervene and the latency of each subject's response. The latency of helping response was the time in seconds it took for a subject to intervene after the onset of the emergency. This was determined by the interval on the chart between the beginning of the emergency and the recording of the subjects' intervention. Those not intervening within 2 minutes were assigned a response latency of 120 seconds.

Postexperimental measures. The postexperimental questionnaire contained three items designed to check on the cohesiveness manipulation. Each item was answered on a 7-point scale, where 1 (labeled "not at all") meant low degree of perceived cohesiveness and 7 (labeled "very much") meant high degree of perceived cohesiveness. The questions were (a) "To what extent would you be willing to talk about intimate/personal topics with all five people you met today?"; (b) "To what extent would you like to meet with these same people again?"; and (c) "How much did you enjoy the conversation with these people?"

Because diffusion of responsibility has been typically conceptualized in terms of the bystander's expectation that others are intervening or will soon intervene (Bickman, 1971), a question was designed to assess this expectation: (d) "To what degree did you expect that someone else would respond to the man's need for assistance?"

This item was answered on a 7-point scale, where 7 (labeled "not at all") meant low expectancy and 1 (labeled "very much") meant high expectancy. The diffusion-of-responsibility hypothesis predicts that in low-cohesive groups, subjects in a four-person group should expect that it is more likely that one of the others would intervene than should subjects in a two-person group. In high-cohesive groups, this tendency should be even more pronounced. Because high cohesiveness is assumed to enhance conformity pressure, particularly in a fourmember group, the bystanders are more likely to view the intervention as a socially expected response. Therefore, they may be more likely to project this expectation to others. 
Table 1

Percentages of Intervening Subjects and Mean

Response Latency (in Seconds) as a Function of Group Cohesiveness and Group Size

\begin{tabular}{|c|c|c|c|}
\hline \multirow{2}{*}{$\begin{array}{c}\text { Dependent } \\
\text { variable }\end{array}$} & \multicolumn{2}{|c|}{ Group size } & \multirow{2}{*}{$\begin{array}{c}\text { Margina } \\
\text { means }\end{array}$} \\
\hline & Two & Four & \\
\hline \multicolumn{4}{|c|}{ High cohesiveness } \\
\hline $\begin{array}{l}\text { \% intervening } \\
\text { Latency }\end{array}$ & $\begin{array}{l}46.7 \\
77.4\end{array}$ & $\begin{array}{l}68.9 \\
56.5\end{array}$ & $\begin{array}{l}57.6 \\
67.1\end{array}$ \\
\hline$n$ & 30 & 29 & 59 \\
\hline \multicolumn{4}{|c|}{ Low cohesiveness } \\
\hline $\begin{array}{l}\text { \% intervening } \\
\text { Latency }\end{array}$ & $\begin{array}{l}55.2 \\
71.3\end{array}$ & $\begin{array}{l}25.8 \\
94.7\end{array}$ & $\begin{array}{l}40.0 \\
83.4\end{array}$ \\
\hline$n$ & 29 & 31 & 60 \\
\hline \multicolumn{4}{|c|}{ Marginal means } \\
\hline $\begin{array}{l}\text { \% intervening } \\
\text { Latency }\end{array}$ & $\begin{array}{l}50.8 \\
74.4\end{array}$ & $\begin{array}{l}46.7 \\
76.2\end{array}$ & $\begin{array}{l}48.7 \\
74.9\end{array}$ \\
\hline$n$ & 59 & 60 & 114 \\
\hline
\end{tabular}

A question was included to assess directly the amount of responsibility for helping assumed by the bystander: (e) "How. responsible do you feel you were for assisting the man?" This question was answered on a 7-point scale, where 7 (labeled "not at all") meant no responsibility and 1 (labeled "very much") meant high responsibility.

The hypothesis tested in this study was that cohesiveness affects helping behavior via change in assumed responsibility for help. High cohesiveness was predicted to increase personal responsibility for helping as group size increases, whereas low cohesiveness was predicted to decrease this responsibility.

\section{Results}

Manipulation check. The success of the cohesiveness manipulation was assessed by analyses of variance performed on the three items of the postexperimental questionnaire. On two items, the mean differences between high and low cohesiveness were statistically significant. Subjects in the high-cohesive groups, compared with those in the low-cohesive groups, expressed a greater desire to meet these same people again, $F(1,115)=$ $11.52, p<.01(M \mathrm{~s}=5.03$ and 4.20 , respectively), and expressed greater enjoyment of the group interaction, $F(1,115)=68.52, p<$ $.01(M s=5.37$ and 3.23, respectively). Subjects in the high-cohesive groups tended to express greater willingness to talk about intimate topics than did subjects in the lowcohesive groups, although the difference was not significant. The analyses revealed no other significant effects.

Approximately $17 \%$ of all subjects were clearly suspicious of the reality of the emergency. Because the level of suspicion did not differ by condition, the suspicious subjects' data were excluded from the analyses. The results are the same if their data are included.

Bystander intervention. Rates of intervention and mean response latencies in the four experimental conditions are presented in $\mathrm{Ta}$ ble 1. As predicted, when cohesiveness was low, a greater proportion of subjects intervened in two-person groups than in four-person groups, whereas this pattern was reversed when group cohesiveness was high. Log-linear analysis (Dixon \& Brown, 1979; Fienberg, 1980) of these frequencies revealed a significant interaction: likelihood ratio chi-square or $G^{2}(1)=8.33, p<.004$. Log-linear analysis is a procedure for testing whether main effects and interactions significantly improve prediction in multiway frequency tables. A hierarchy of models is constructed such that each succeeding model adds a new main effect or interaction as a predictor. Each model is tested for its goodness of fit to the data and for its improvement in prediction over the preceding model. In the present data, models that included only the marginals or the marginals and main effects of group size and cohesiveness provided inadequate goodness of fit. The model created by adding the interaction of these variables produced a significantly better fit than the model comprising the marginals and both main effects.

An analysis of variance employed in assessing the effects of group cohesiveness and group size on response latency revealed that the predicted interaction was significant, $F(1$, $115)=6.65, p<.01$. There were no other significant effects. Consistent with the hypothesis, in the low-cohesive condition, responses in the four-person groups were significantly slower than responses in the two-person groups, $t(58)=1.97, p<.05$ (onetailed test). In the high-cohesive condition, responses in the four-person groups were significantly faster than responses in the twoperson groups, $t(57)=1.67, p<.05$ (onetailed test). 
Postexperimental questionnaire. An analysis of variance performed on the items of the postexperimental questionnaire revealed significant main effects for cohesiveness. Compared to the subjects in low-cohesive groups, those in high-cohesive groups reported more responsibility for helping, $F(1$, $115)=4.09, p<.05$, and had stronger expectations that someone else would respond, $F(1,115)=4.32, p<.05$. There were no other significant effects.

\section{Discussion}

The hypothesized impact of group cohesiveness on bystander intervention was obtained. In the low-cohesive groups, larger group size inhibited helping, a finding that replicates the results of previous research (cf. Latane \& Nida, 1981). In contrast, in the high-cohesive groups, larger group size facilitated helping, which is a reversal of the often-obtained bystander-intervention effect. Apparently, high cohesiveness not only prevented diffusion of responsibility from occurring but actually increased individual responsibility for help as the number of bystanders increased.

Group cohesiveness presumably operates by increasing motivation to conform to group norms. This would suggest that behavioral effects of cohesiveness should depend on the salience and/or content of a group norm. In support of this assumption, Berkowitz (1954) demonstrated that high-cohesive groups produced more that low-cohesive groups under a high-productivity norm, but with a low-productivity norm, high-cohesive groups inhibited productivity to a greater extent than low-cohesive groups. Thus, cohesiveness can be expected to interact with any variable that changes the salience or content of a group norm.

We assumed that the social-responsibility norm was salient in our emergency situation and that cohesiveness increased responsiveness to this norm. If this reasoning is correct, we would expect cohesiveness to influence helping more when the social-responsibility norm is salient than when it is not.

Study 2 was designed to test this hypothesis. One component of the social-responsibility norm that is likely to affect its salience is the degree of the victim's need for help.
When the victim's need is slight, the socialresponsibility norm is less likely to be invoked than when the victim's need is severe. Need for help may be defined as the utility of help or how much benefit the help may produce (Gruder, 1974; Staub, 1974). According to this reasoning, cohesiveness should have its greatest impact on intervention when the victim's need is great. When the victim has less need, the effect of cohesiveness should be attenuated.

\section{Study 2}

\section{Method}

Subjects and design. A total of 48 male undergraduates volunteered for the experiment and received course credit in return for their participation. Three-person groups were randomly constituted and assigned to four conditions in a $2 \times 2$ (Cohesiveness $\times$ Need for Help) factorial design, with 12 subjects in each condition.

Procedure. With a few exceptions, the procedure was the same as that of Study 1. Most notably, subjects did not see the future victim. The experimental task was explained to them in the laboratory, where the emergency later occurred. In this laboratory, various items, such as a ladder, a set of tools, and some light bulbs, were arranged to give the impression that maintenance work was in progress. Another difference was that subjects in the low-cohesive condition, instead of listening to a tape recording, wrote a few sentences about themselves and provided a brief written reply to the topics during the cohesiveness-inducing procedure.

The experimental rooms in which subjects were seated were equipped with microphones and loudspeakers (instead of headphones). After the experimenter announced over the loudspeakers that he was leaving the laboratory, subjects heard the future victim enter the laboratory and approach the experimenter; these events had been tapdrecorded and were played back to subjects. In the condition in which the victim's need for help was great, the following short dialog took place:

Victim: "Hi, I'm sorry to interrupt you, but I was supposed to finish some work here."

Experimenter: "Hello, I haven't seen you around lately. How are you doing?"

Victim: "Y've been in the hospital for some time, but I still feel weak."

Experimenter: "Oh, I'm sorry to hear that. So . . . you're gonna work here? But, there is an experiment in progress."

Victim: "It'll only take a minute."

Experimenter: "That's fine. Then, I'll see you later."

When the victim's need for help was low, the dialog was slightly changed so that the victim explained his absence as follows: "I have been on vacation for some time and I feel great." The experimenter replied, "Oh, that's good. So . . . you're gonna work here? But there is an experiment in progress." 
Table 2

Percentages of Intervening Subjects as a Function of Group Cohesiveness and the Degree of Need for Help

\begin{tabular}{lccc}
\hline & \multicolumn{2}{c}{ Cohesiveness } & \\
\cline { 2 - 3 } \multicolumn{1}{c}{ Need } & Low & High & $\begin{array}{c}\text { Marginal } \\
\text { means }\end{array}$ \\
\hline High & 0 & 87.5 & 46.7 \\
Low & 7 & 8 & 15 \\
$n$ & 22.2 & 33.3 & 26.7 \\
Marginal means & 12.5 & 64.3 & 36.7 \\
$n$ & 16 & 14 & 30 \\
\hline
\end{tabular}

The dependent measure was the frequency of helping responses. Latency of helping response was not measured.

\section{Results}

Manipulation checks. Compared to lowcohesive groups, high-cohesive groups expressed greater willingness to discuss sensitive personal material, $F(1,28)=5.08, p<$ $.05(M s=2.94$ and 3.57 , respectively), and more enjoyment of group interaction, $F(1$, $28)=7.63, p<.025(M$ s were 3.19 and 4.19, respectively). There were no other significant effects. The difference between high- and lowcohesive groups in their desire to meet with these same persons in another experiment, although in the expected direction, was not significant.

The difference in the perception of the need for help ("weak" vs. "healthy" victim) was tested with an independent sample of 24 undergraduate students drawn from the same population. One half of the students listened to the tape recording of the weak victim and the other half listened to the recording of the healthy victim. They then rated the victim on a 7-point scale (where 7 meant greatest need for help). The weak victim was perceived as requiring more help than the healthy victim, $F(1,22)=6.85, p<.025$ $(M \mathrm{~s}=6.83$ and 5.33 , respectively).

In the postexperimental interviews, $38 \%$ of all subjects expressed suspicions about the reality of the emergency. The distribution of suspicious subjects did not differ significantly across experimental conditions. Their data were excluded from the analysis; the results are the same, though, if they are included.

Bystander intervention. The rates of intervention are presented in Table 2. As predicted, high cohesiveness increased intervention more when need was high than when it was low. Log-linear analysis revealed that the model that included the interaction of cohesiveness and need provided a significantly better fit of these frequencies than models that included only the marginals or the marginals and main effects of these variables, $G^{2}(1)=6.32, p<.012$. There was also a significant main effect of cohesiveness; although it did not provide an adequate fit of the data, the model that included only the marginals and the main effect of cohesiveness provided a significantly better fit than the marginals alone, $G^{2}(1)=9.13, p<.005$.

\section{Discussion}

The results were consistent with predictions. High cohesiveness dramatically increased the frequency of helping when the victim of the emergency appeared to be in great need of help. A somewhat unexpected finding was that no bystanders intervened in the low-cohesiveness/high-need condition. This condition seems to characterize the events that gave rise to research on bystander intervention-the murder of Kitty Genovese (Darley \& Latané, 1968). Despite the victim's very great need (which presumably made the social-responsibility norm salient), the low cohesiveness among the bystanders provided little social pressure to comply with the prescription to help. Thus, the bystanders might have felt more justified to assume that others had already or would soon help, so their assistance was not necessary.

At least two aspects of the experimental procedure might have contributed to lowering the credibility of the emergency and thus enhancing suspicion. First, subjects had no opportunity to see the future victim. In Study 1 subjects did see the future victim before the accident, and the level of suspicion was minimal. Second, the tape-recorded distress sounds were played through loudspeakers, perhaps making the accident sound artificial. In Study 1 subjects heard the accident through headphones, which transmit with higher quality. 


\section{General Discussion}

In two controlled laboratory studies, we examined the impact of group cohesiveness on bystander intervention. In Study 1 we demonstrated that cohesiveness among bystanders reverses the typical inhibitory effect of group size on helping in an emergency. When bystanders were cohesive, they were more likely to intervene in larger groups than in smaller groups. In Study 2 we showed that cohesiveness increases helping when the social-responsibility norm, which prescribes helping, is salient.

We interpreted these findings in terms of small-group processes. The underlying assumption was that cohesiveness increases group members' motivation to conform to group norms. Thus, it follows that this conformity pressure is greater in larger groups that in smaller ones and greater when the norm is salient than when it is not.

There are, however, some alternative explanations for the effects of our cohesiveness manipulation. One is that subjects in the high-cohesive groups may have expected future interaction and, therefore, were more helpful. This seems unlikely, though, for two reasons. First, Gottlieb and Carver (1980) found that the expectation of future interaction diminished the bystander effect but did not reverse it. Our cohesiveness manipulation did reverse this effect. Second, our subjects were unlikely to expect to interact with each other following the experiment because the subject pool was relatively large (over 1,000 students) and all were commuter students who did not live on campus.

Another explanation follows from Zimbardo's (1969) theory of deindividuation. Low cohesiveness in larger groups affords anonymity and thereby can facilitate nonnormative behavior. High cohesiveness, in contrast, individuates the subjects and thereby may promote prosocial behavior. We believe that cohesiveness is a multidimensional concept that includes the expectation of future interaction and individuation as well as attraction. Future research should be designed to investigate the importance and effects of each of these components on prosocial behavior.

In this research, we have begun to address the question raised by Latané and Nida
(1981) concerning the conditions that facilitate helping in emergencies. As they noted, the focus of research has been the counterintuitive finding that helping is inversely related to group size. This was undeniably an important and startling finding. We feel, however, that the present research identifies two critical factors that affect the group-sizehelping relation-social norms and group cohesiveness.

The present studies underscore the importance of psychological relationships among bystanders for understanding their behavior in emergencies. These relationships can be described on a continuum ranging from total lack of cohesiveness (i.e., individuals do not know the bystanders who are present), through low cohesiveness (i.e., individuals know the bystanders who are present, but they are basically still strangers), to greater degrees of cohesiveness among bystanders. On the one hand, Darley and Latané (1968) and other investigators found inhibition of helping under conditions of total noncohesiveness, and we also found this inhibition under the low-cohesiveness conditions in Study 1 . On the other hand, Gottlieb and Carver (1980) found no inhibition of helping when the bystanders anticipated future interaction; this anticipation may have induced a moderate degree of cohesiveness. Finally, in the high-cohesiveness conditions of Study 1 , we found a facilitation of helping. Horowitz (1971) also found a reversal of the bystander effect among members of social-service groups for whom the norm of helping is presumed to be a primary group norm. This effect was especially pronounced when the members' identification with the group was enhanced. Thus, it appears that the cohesiveness dimension captures a critical aspect of intragroup dynamics that may be responsible for either inhibition or facilitation of helping behavior in emergencies.

Latané and Nida (1981) concluded their review of 10 years of research on group size and emergency helping somewhat pessimistically by noting that it has contributed little to the development of practical strategies for increasing bystander intervention. The results of our studies have clear implications for developing such strategies. In fact, a program designed to stimulate bystander responsiveness, and actually based on the idea 
of increasing community cohesiveness, has already been successfully implemented in New York City (Sheperd, 1973). In this program, cohesiveness was enhanced by fostering activities designed to get people to know one another better. Hackler, Ho, and Urguhart-Ross (1974) found, in a field study, that increased interaction within urban communities was positively related to intentions to intervene in hypothetical neighborhood emergencies.

The main assumption of the present studies can be applied to a different behavioral domain: "social loafing" (Latané, Williams, \& Harkins, 1979). People exhibit a significant decrease in individual effort when performing in groups as compared to when they perform alone. This is so presumably because the responsibility for work is diffused in much the same fashion as the responsibility for help. However, cohesiveness may intensify individual responsibility for work, and there exists some evidence in support of this hypothesis $(\mathrm{Ex}, 1959)$.

\section{References}

Berkowitz, L. Group standards, cohesiveness and productivity. Human Relations, 1954, 7, 509-519.

Berkowitz, L. Social norms, feelings and other factors affecting helping and altruism. In L. Berkowitz (Ed.), Advances in experimental social psychology. New York: Academic Press, 1972.

Berkowitz, L., \& Daniels, L. R. Responsibility and dependency. Journal of Abnormal and Social Psychology, $1963,66,429-436$.

Bickman, $L$. The effect of another bystander's ability to help on bystander intervention in an emergency. Journal of Experimental Social Psychology, 1971, 7, 367379.

Bryan, J. A., \& Test, M. A. Models and helping: Naturalistic studies in aiding behavior. Journal of Personality and Social Psychology, 1967, 6, 400-407.

Cartwright, D. The nature of group cohesiveness. In D. Cartwright \& A. Zander (Eds.), Group dynamics: Research and theory (3rd ed.). New York: Harper \& Row, 1968.

Darley, J. M., \& Latané, B. Bystander intervention in emergencies: Diffusion of responsibility. Joumal of Personality and Social Psychology, 1968, 8, 377-383.

Dion, K. L., Miller, N., \& Magnan, M. N. Cohesiveness and social responsibility as determinants of group risk taking. Journal of Personality and Social Psychology, $1971,20,400-406$.

Dixon, W. J., \& Brown, M. B. (Eds.). BMDP-79: Biomedical computer programs P-series. Los Angeles: University of California Press, 1979.

Ex, J. The nature of contact between co-operating persons and their expectancy concerning the level of their common achievement. Acta Psychologica, 1959, 16, 99-107.

Fienberg, S. E. The analysis of cross-classified categorical data (2nd ed.). Cambridge, Mass.: MIT Press, 1980.

Gottlieb, J., \& Carver, C. S. Anticipation of future interaction and the bystander effect. Journal of Experimental Social Psychology, 1980, 16, 253-260.

Gruder, C. L. Cost and dependency as determinants of helping and exploitation. Journal of Conflict Resolution, 1974, 3, 473-485.

Gruder, C. L., Romer, D., \& Korth; B. Dependency and fault as determinants of helping. Journal of Experimental Social Psychology, 1978, 14, 227-235.

Hackler, J. C., Ho, K., \& Urguhart-Ross, C. The willingness to intervene: Differing community characteristics. Social Problems, 1974, 3, 328-344.

Horowitz, J. A. The effect of group norms on bystander intervention. Journal of Social Psychology, 1971, 83, 265-273.

Jones, E. E., \& Gerard, H. B. Foundations of social psychology. New York: Wiley, 1967.

Kogan, N., \& Wallach, M. A. Risk taking: A study in cognition and personality. New York: Holt, Rinehart \&. Winston, 1964.

Latané, B., \& Darley, J. M. The unresponsive bystander: Why doesn't he help? New York: Appleton-CenturyCrofts, 1970.

Latané, B., \& Nida, S. Ten years of research on group size and helping. Psychological Bulletin, 1981, 89, 308-324.

Latané, B., Williams, K., \& Harkins, S. Many hands make light the work: The causes and consequences of social loafing. Journal of Personality and Social Psychology, 1979, 37, 822-832.

Lott, A., \& Lott, B. A. Group cohesiveness as interpersonal attraction: A review of relationship with antecedent and consequent variables. Psychological Bulletin, 1965, 4, 259-309.

Morgan, C. J. Bystander intervention: Experimental test of a formal model. Journal of Personality and Social Psychology, 1978, 36, 43-55.

Pfeiffer, J. W., \& Jones, J. E. (Eds.). Structured experience kit. San Diego, Calif:: University Associates, 1980.

Ross, A. S. The effect of observing a helpful model on helping behavior. Journal of Social Psychology, 1970, $1,131-132$

Schwartz, S. The justice need and the activation of humanitarian norms. Journal of Social.Issues, 1975, 31, 111-136.

Sheperd, J. A west side report. New York, October 15, $1973,6,58 ; 63$.

Staub, E. Helping a distressed person: Social, personality and stimulus determinants. In L. Berkowitz (Ed.), Advances in experimental social psychology (Vol. 7). New York: Academic Press, 1974.

Zimbardo, P. G. The human choice: Individuation, reason, and order versus deindividuation, impulse, and chaos. In W. J. Arnold \& D. Levine (Eds.), Nebraska Symposium on Motivation (Vol. 17). Lincoln: University of Nebraska Press, 1969.

Received May 21, 1982

Revision received August 23, 1982 